\title{
Investigation of Imbalance Faults in Horizontal Axis WTGS through Analysis of Generator Current Signal
}

\author{
Abdul Sattar1, 2, Imtiaz Hussain1, Tayab Din Memon', Haider Karar', Umair Saeed² \\ 'Department of Electronics, Mehran University of Engineering and Technology, Jamshoro, Pakistan; \\ sattarnoonari@gmail.com, imtiaz.hussain@faculty.muet.edu.pk, \\ tayabdin82@gmail.com, haiderkararnoonari@gmail.com \\ 2Department of Electronics, Quaid-e-Awam University of Engineering, Science and Technology, Nawabshah, \\ Pakistan; lec.umair25@gmail.com
}

\begin{abstract}
This paper presents imbalance faults investigation of wind turbine system through generator's current signal. A simulation model of wind turbine generator is developed in MATLAB and FAST (Fatigue, Aerodynamics, Structure and Turbulence) to carry out simulations. Various imbalance faults are introduced in wind turbine's mechanical system using FAST. Simulink is further used to feed turbine data in permanent magnet synchronous machine and capture current signal. It has been observed that any changes appearing in rotating frequency of wind turbine can be measured by utilization of appropriate sensors i.e. torque sensor. This observation has been taken to next stage by analyzing generator's current signal at ground station for fault detection. This is because the mechanical link of turbine's shaft to that of generator, associates variations appearing in fundamental shaft frequency of turbine with current or voltage output of generator. Using simple FFT, current signal is analyzed for imbalance fault excitations. Through all simulations it has been strongly observed that when aerodynamic asymmetry or blade imbalance fault is introduced in system, excitations in current signal of generator appear at turbine's fundamental rotating frequency. Multiple scenarios like altering mass or pitch of one or multiple blades of three-bladed turbine are simulated. All of which have shown same pattern of excitations as stated earlier. This method of fault investigation does not need any additional sensors or climbing up of turbine. Moreover, current signal analysis results can be compared with previous normal results to seize any other abnormalities in WTGs behavior.
\end{abstract}

Keywords: Aerodynamic Asymmetry, Blade Imbalance, FAST, Imbalance Faults, Wind Turbine

\section{Introduction}

The concept of energy extraction from wind started in late $19^{\text {th }}$ century ${ }^{1}$ and rapid grown in the areas of aerodynamics, power electronics and control systems has made conditions favorable to make bigger wind machines. Currently, wind machines as big as producing $08 \mathrm{MW}$ are being built (for example - Vestas V164-08MW)ํ․ This much power capability comes with more wear and expensive faults. It has been reported that annually an average wind turbine does not produce electric power for 52-237 hours $^{3}$ due to installation, dynamic load, bad weather and aging issues. The maintenance time required for wind turbine may be as high as 50 times to the actual cost of a typical component excluding the loss incurred due to no power generation ${ }^{3}$. Generally faults introduced into

${ }^{*}$ Author for correspondence 
the wind turbine are due to varying load and atmospheric conditions like wind shear and turbulent wind gust which change the magnitude and direction of wind often, put an adverse effect on overall life of turbine. With span of time, wear and tear in turbine mechanics accumulates to produce a big fault, ceasing the operation of turbine. To tackle this, online condition monitoring is very much useful to proactively look for such faults. With online condition monitoring reliability of wind turbine system is increased while maintenance cost is reduced. In this paper various simulation based studies are carried out to figure out the possibility of detecting faults from turbine generator current signal. To serve this purpose Simulink from MATLAB and FAST 7.0 from National Renewable Energy Laboratory (NREL) is used.

\section{WTG Model and Imbalance Faults}

Figure 1 shows the overall setup in which a wind turbine machine is connected to grid station. At this grid station we receive three phase output from which only one phase is selected. This selected phase is then analyzed for imbalance fault signatures.

\subsection{Wind Conditions}

Wind conditions have been obtained from FAST 7.0 software library.

FAST 7.0 comes with a set of default test cases in which different parameters are defined. We can select between

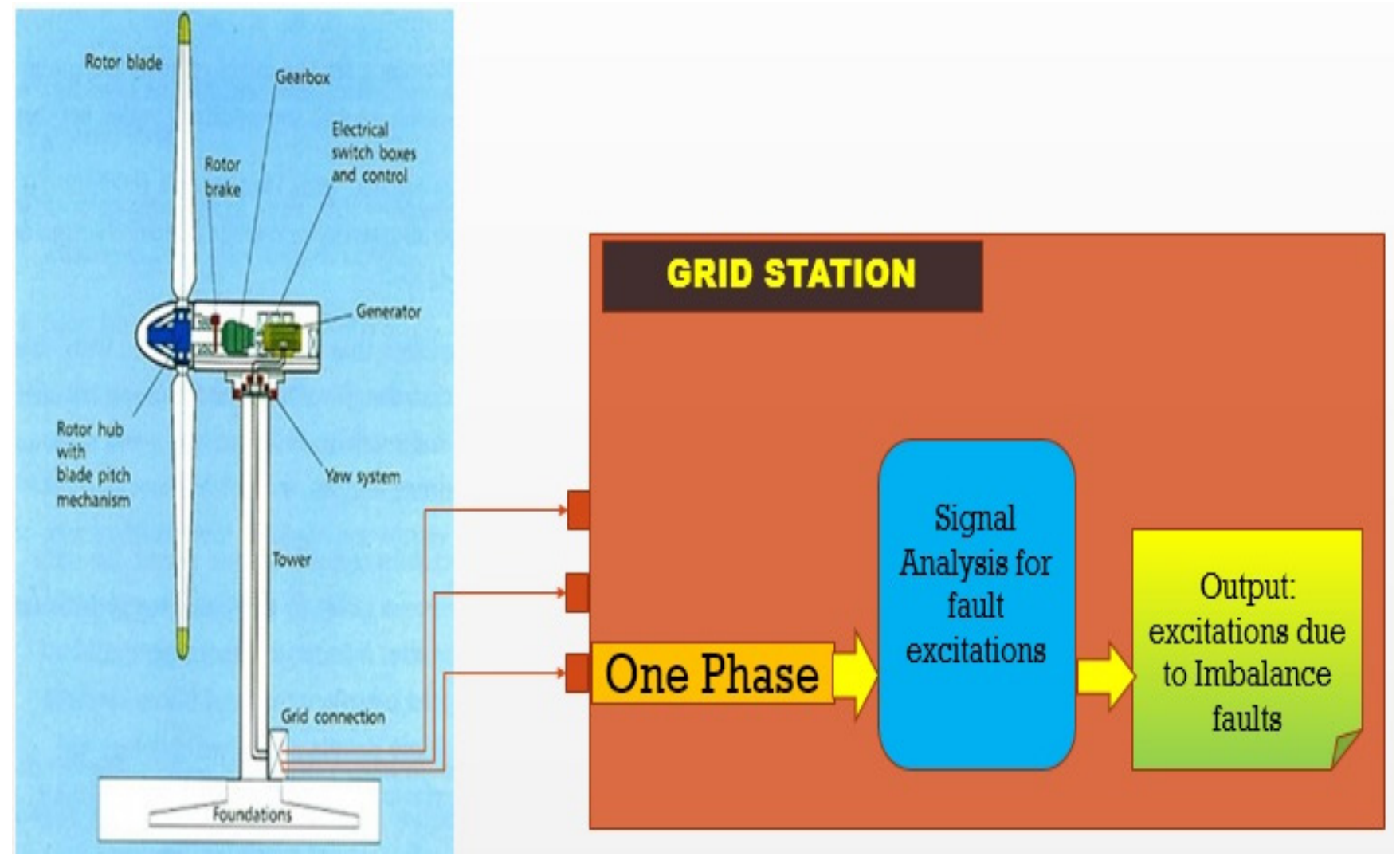

Figure 1. Wind Turbine Feeding Output to Grid Station. 


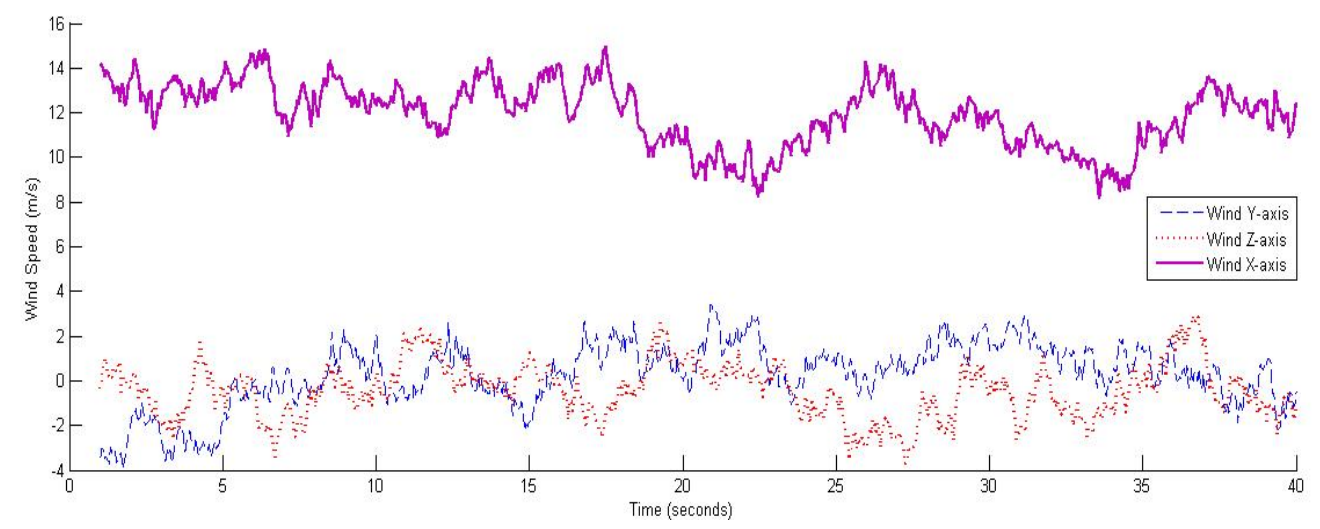

Figure 2. Wind Speed Variations.

constant wind and variable wind conditions using settings test available in case files. In this paper we have used variable wind conditions, with turbulence involved to get more realistic results.

Wind speed within range of 08 to 14 meters/second and turbulence have been taken into effect while doing simulations put forwarded here. Figure 2 shows various wind velocity components (in $\mathrm{X}, \mathrm{Y}$ and $\mathrm{Z}$ dimensions) that are taking part to drive wind turbine blades. Major wind velocity component appears in $\mathrm{X}$-axis direction.

\subsection{Blade Imbalance Fault Theory}

A wind turbine system is said to have gone through a blade imbalance fault when there is unequal mass distribution among its blades, resulting in unequal centrifugal forces from different blades ${ }^{3}$.

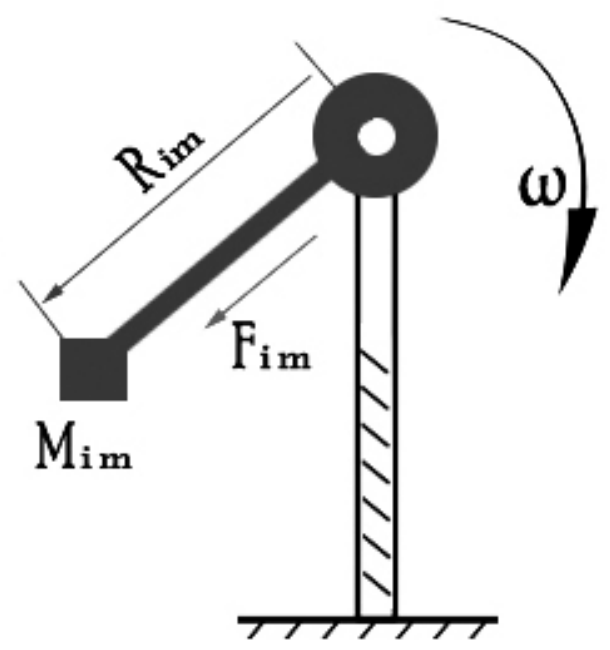

Figure 3. Blade Imbalance Due to Unsought Mass. 
In general, this imbalance fault generates a novel force in main shaft, termed as $\mathrm{F}_{\mathrm{im}}$. The rotary speed of this force is equal to turbine's rotary speed. $\mathrm{F}_{\mathrm{im}}$ is centrifugal by nature ${ }^{4}$ and given by:

$$
F_{i m}=M_{i m} R_{i m} \omega^{2}
$$

Where, $M_{i m}$ is the revolving mass in kilograms causing imbalance, $R_{i m}$ is the radius of circular path made by $M_{i m}$. and $\omega$ is the angular speed of shaft $[\mathrm{m} / \mathrm{s}]$.

In case of blade imbalance fault, gravity plays a vital role. When an imbalance mass moves from top to bottom, it increases the " $\omega$ ". When the same imbalance mass moves from bottom to top it decreases " $\omega$ ". This speed fluctuation can be seen in " $\omega$ " value of WTG at the frequency range of $1 \mathrm{P}^{5}$.Thus characteristic frequency of blade imbalance fault affiliated with main shaft revolving frequency, also termed as "1P-frequency" ${ }^{\prime \prime, 7}$.

\subsection{Aerodynamic Imbalance Fault Theory}

The energy extracted from wind heavily depends upon the angle at which a blade interacts with wind. Aerodynamic imbalance fault refers to a condition when one or more blades produce different amount of torque compared to other blades. Therefore, due to uncared settings of blade pitch angle or improper blade control mechanisms different blades produce different amount of torque within single turbine resulting blade imbalance fault $\stackrel{\underline{*}}{\text {. }}$

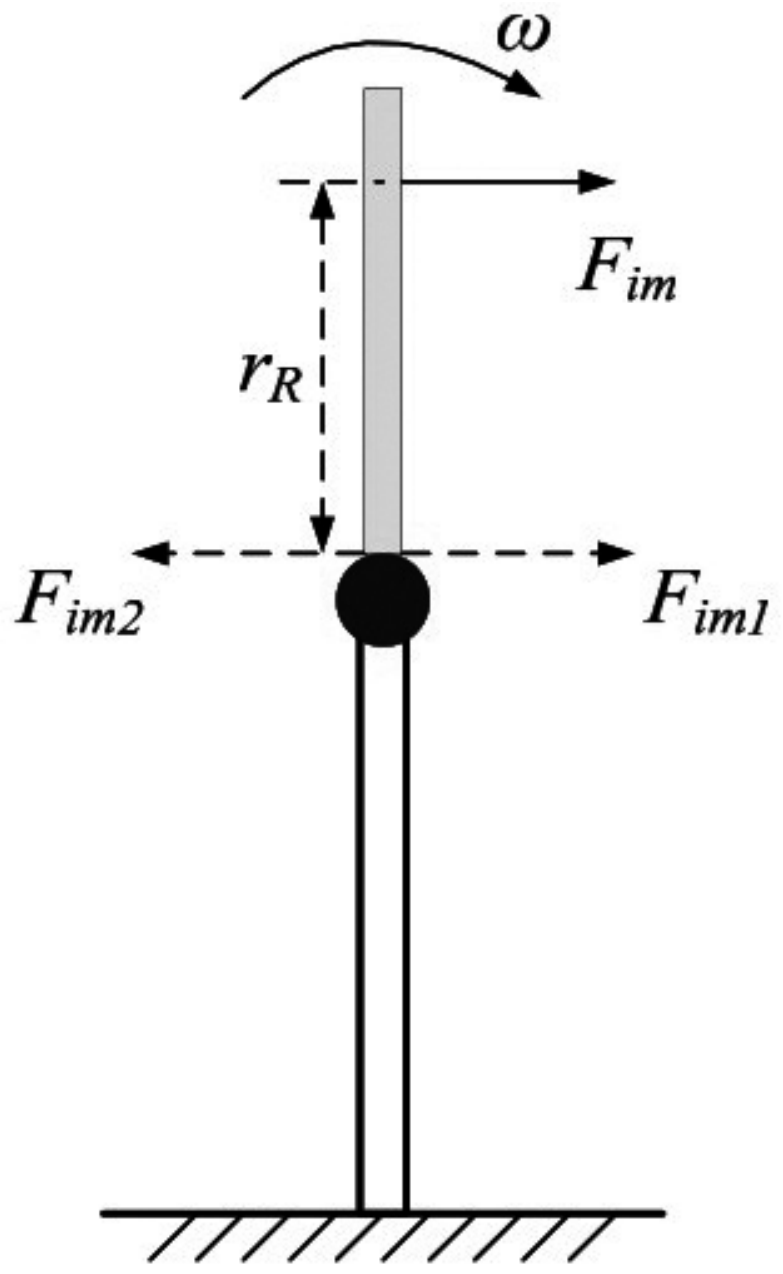

Figure 4. Aerodynamic Imbalance Due to Unsought Pitch Angle. 
" $F_{i m}$ " is the imbalance force introduced on shaft when in aerodynamic asymmetry fault is observed by system ${ }^{3}$. It is calculated as:

$$
F_{i m}=\frac{T_{a}}{r_{a}}
$$

Where $\mathrm{T}_{\mathrm{a}}$ is aerodynamic-asymmetry torque and $\mathrm{r}_{\mathrm{a}}$ is length of force-arm of $\mathrm{T}_{\mathrm{a}}$.

In figure (4), three forces acting on WTG blades are shown. Among those forces, Fim and Fim2 generate the actual productive torque while Fim 1 creates oscillatroyforce in the shaft $\mathrm{fi}^{\frac{34}{3}}$.

When aerodynamic asymmetry is observed by system, both the acceleration and deceleration of the faulty-blade generates vibrations at the $1 \mathrm{P}$ frequency ${ }^{4}$ in the shaft revolving speed.

\subsection{Characteristic Frequencies of Imbalance Faults}

Studies have proved that behavior of torque in relation to electric power for 03 bladed wind machine is governed by specific moments. Taking " $\mathrm{P}$ " as fundamental frequency, the excitations at " $3 \mathrm{P}$ " are the result of wind-shear, towershadow or yaw-error $\frac{7.9}{}$. In same way, excitations at $1 \mathrm{P}$ frequency are result of imbalance faults i-e blade/aerodynamic asymmetry fault ${ }^{4,6,10,11}$.

In directly driven WTGs, 01-mass model of $s$

haft system is represented through following equations:

$$
\begin{aligned}
& \left(\frac{d \omega_{r}(t)}{d t}\right) \cdot J=T_{t}(t)-\left[T_{\theta}(t)+D \cdot \omega_{r}(t)\right] \\
& \omega_{r}(t)=2 \pi f_{r}(t)
\end{aligned}
$$

Where,

$\mathrm{J}=$ "total inertia constant"

$\omega_{\mathrm{r}}=$ "angular speed $[$ shaft $]$ "

$\mathrm{f}_{\mathrm{r}}=\mathrm{WTG}$ shaft revolving frequency $=1 \mathrm{P}$ frequency

$=$ Angular acceleration
$\mathrm{T}_{\mathrm{t}}=$ Total torque,

$\mathrm{T}_{\mathrm{e}}=$ Torque of the generator,

$\mathrm{D}=$ Damping-coefficient .

Equation 3 effectively presents a linear model which shows shaft speed-torque relation of wind machine. It is obvious that vibrations in the torque(s) of the WTG i.e. due to imbalance faults, will cause similar vibrations in the shaft speed " $\omega$ " and consequently in power output of generator.

\section{Simulation Platform}

\subsection{Setting Up FAST 7.0}

National Renewable Energy Laboratory (NREL) has created FAST 7.0 (Fatigue, Aerodynamic, Structure and Turbulence) to simulate the dynamic behavior of turbines. Here, FAST 7.0 is integrated with Simulink in order to simulate imbalance faults. This needs configuration before simulation. It accepts files with "ffst" extension which contain several of parameters required for desired operation of FAST 7.0. We have created two different files for two imbalance faults i.e. "AeroImb.fst" and "BladeImb. fst" to carry out simulations.

In "AeroImb.fst" file, pitch angles of three-bladed wind turbine modified to different degrees while in "BladeImb. fst" file, the uniform mass distribution of blade is disturbed to create the effect of blade imbalance. Apart from “.fst" files, FAST 7.0 also accepts direct inputs like torque, yaw position, rate and pitch angles of blades which can also be modified as per need. FAST 7.0 code block accepts four inputs for its operation i.e. generator torque in N.m and power in watts, yaw position of wind turbine in radians and the rate at which yaw control is allowed to work, blade pitch angles in radians and the rate at which blade angles are adjusted when pitch control is activated. Depending on simulation settings and environment these inputs can be enabled or disabled. In this paper, only yaw angle and yaw rate are kept fixed at zero radians and supplied initially through ".fst" file as described above. While 
rest of the inputs keep changing as different fault cases are simulated.

\subsection{Introducing Blade Imbalance}

The FAST 7.0 is packaged with file known as "Baseline_ Blade.dat", responsible for blade structure and properties like blade or edge stiffness, blade or edge mode structural stiffness and mass-density etc. In this paper, we will be focusing on mass-density property. To introduce blade imbalance we'll change the value of "BMassDen" parameter. Changes in its value can be made follows: Open FAST folder and go to "CertTest". Find "Baseline_Blade. dat" and then "BMassDen $[\mathrm{kg} / \mathrm{m}]$ ". Under "BMassDen" parameter, we can find a set of values representing mass density from base to tip of blade. Entering irregular mass density values will help us simulate blade imbalance fault.

\subsection{Introducing Pitch Imbalance}

The aerodynamic-asymmetry in wind machine is introduced by setting pitch-angle of at least one of the blades different from others. The FAST 7.0 supports simulations of aerodynamically asymmetrical behavior of wind machine by providing direct settings for blade pitch angle. The file for providing pitch angle setting of turbine can be found at CerTest folder with ".fst" extension. Parameter responsible for blade pitch angle is "BLPitch" (blade pitch variable). Default value of this variable is " 7.5 degrees" for each blade. Changing the value of one of the blades is will make system go through aerodynamic asymmetry fault.

\subsection{Overall Simulation Setup}

FAST 7.0 computes several parameters related to wind turbine but generates the output of only those which

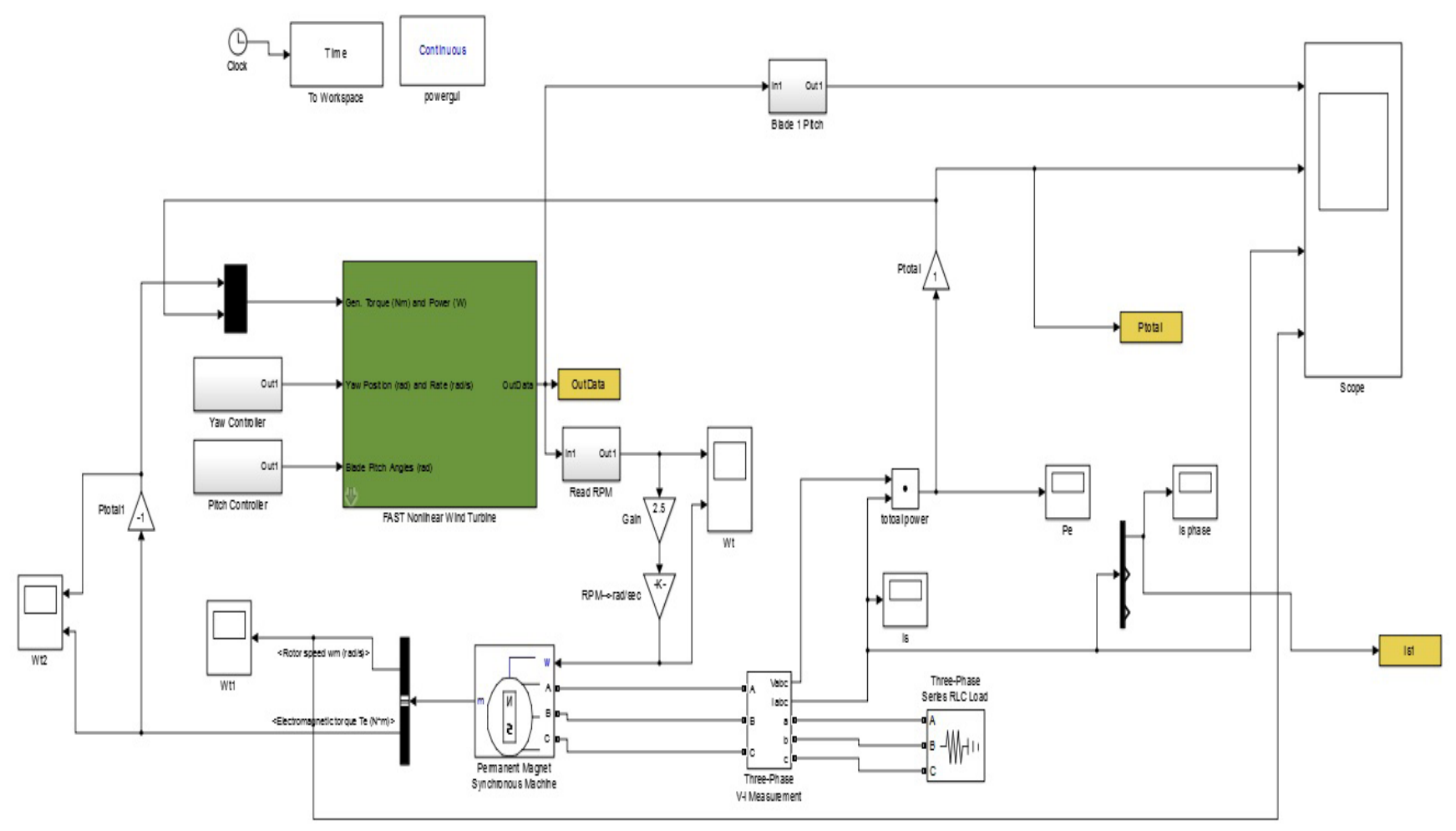

Figure 5. FAST 7.0 Code Block with PMG 
are defined in initial setup file named "OutList". In these simulations, we are particularly interested in shaft rotating speed of wind turbine known as " $1 \mathrm{P}$ ". This parameter is then fed into permanent magnet synchronic machine (PMG) input known as " $\omega$ ". Figure 5 shows the overall simulation setup.

All parameters of PMG used in the simulations are left at default except the number of poles which is set to 02 .

\section{Fault Signature Investigation}

As discussed earlier, the characteristic frequency of imbalance faults in wind turbines lie at $1 \mathrm{P}$ frequency. Involving the effect of turbulence and wind shear, the shaft rotating frequency cannot be uniform. Therefore, some proper method needs to be applied to detect the characteristic frequency of imbalance faults. Since the goal of this paper

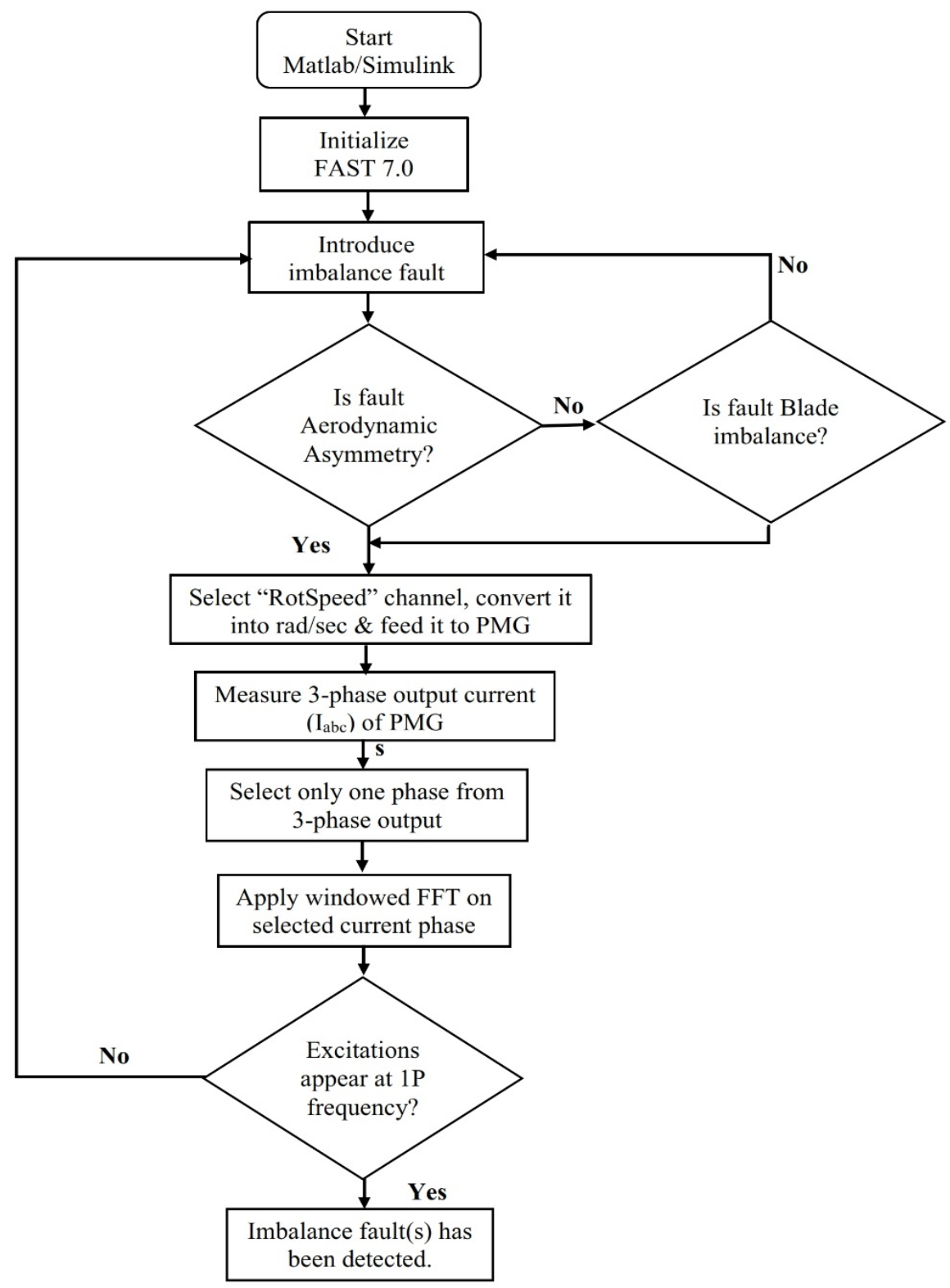

Figure 6. Flowchart for Imbalance Fault Investigation 
is to analyze the efficacy of conventional FFT method on finding characteristic frequency of imbalance faults from current signal hence the modification in conventional FFT process are kept to minimum. However, the problem with this method is that shaft frequency does not revolve at fixed frequency. Depending upon wind conditions it keeps on varying. FFT will not be much effective if it is applied on larger chuck of data signals from turbine generator. To lessen this problem, we have taken smaller chunk of current signal data. In this way the larger variations in frequency of shaft are reduced. Figure 6 depicts steps incorporated to investigate imbalance faults in wind turbine by applying conventional FFT on generator current signal.

\section{Simulation Results}

Simulation results are presented here in two separate categories i.e. for each of imbalance fault.

\subsection{Blade Imbalance Fault Simulations}

\subsubsection{Normal Response}

Before we simulate any fault, system is run at its normal and default values. At the same time, behaviour of phase current is observed. For future reference, this response is termed as "normal case".

Figure 7 shows the current signal analysis of normal response. Where " $1 \mathrm{P}$ " frequency or shaft rotating frequency can be seen at circa 05 hertz.

\subsubsection{Mass Density of One Blade Increased to $2000 \mathrm{~kg} / \mathrm{m}$}

Figure 8 shows the analysis of current signal when only one blade mass density is increased to $2000 \mathrm{~kg} / \mathrm{m}$. While rest of two blades have default mass density distribution. It can be noticed that due this one imbalanced blade excitations in generator current signal at $1 \mathrm{P}$ frequency are observed.

\subsubsection{Mass Density of Two Blades Increased to $2000 \mathrm{Kg} / \mathrm{m}$ and $300 \mathrm{~kg} / \mathrm{m}$}

This fault condition takes the blade imbalance to worst scenario where all three blades have different mass density. Figure 9 shows the analysis of current signal when blade- $01=$ default, blade- $02=2000 \mathrm{Kg} / \mathrm{m}$ increased and blade $-03=300 \mathrm{~kg} / \mathrm{m}$ increased.

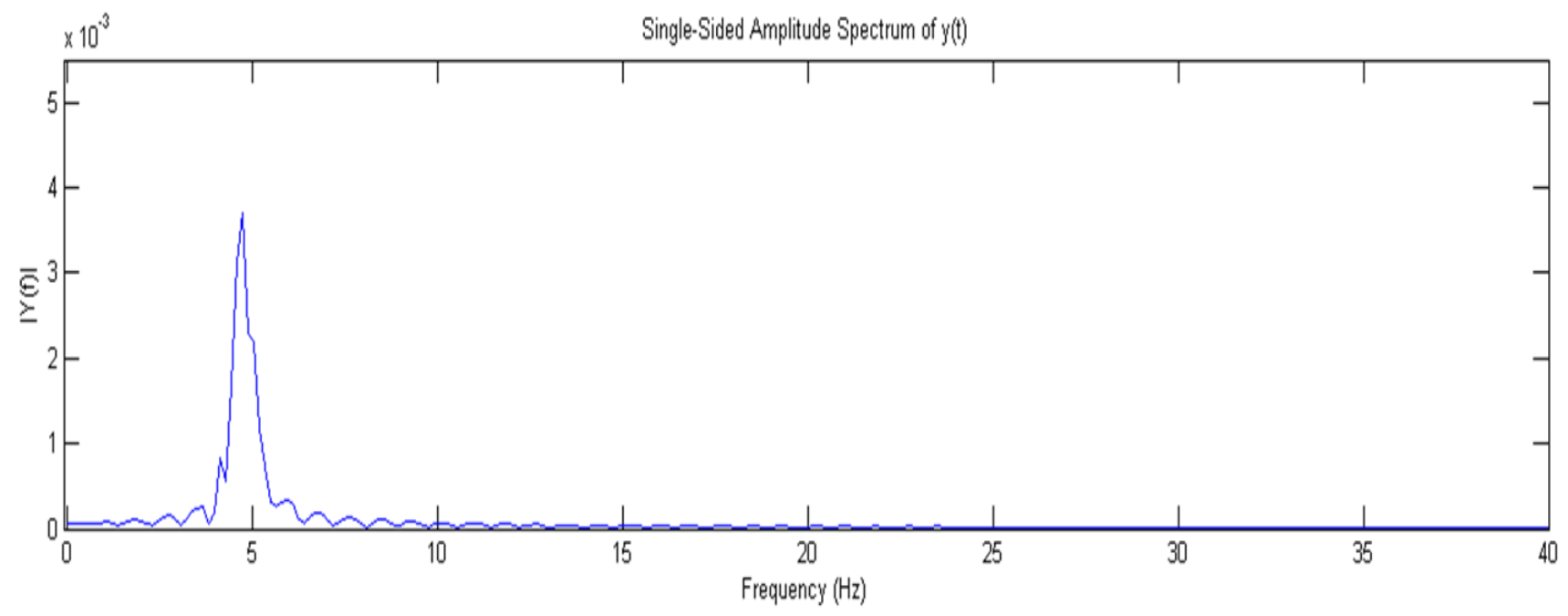

Figure 7. System Baseline or Normal Respone. 


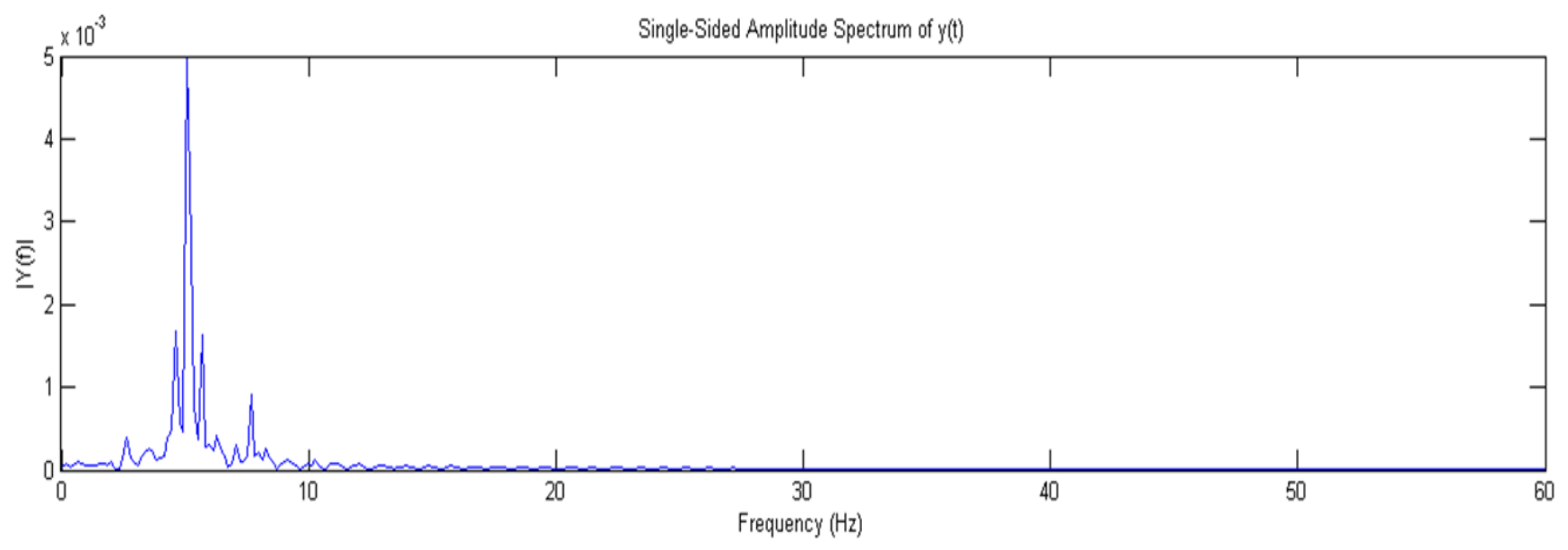

Figure 8. Mass Density of One Blade Increased to $2000 \mathrm{~kg} / \mathrm{m}$.

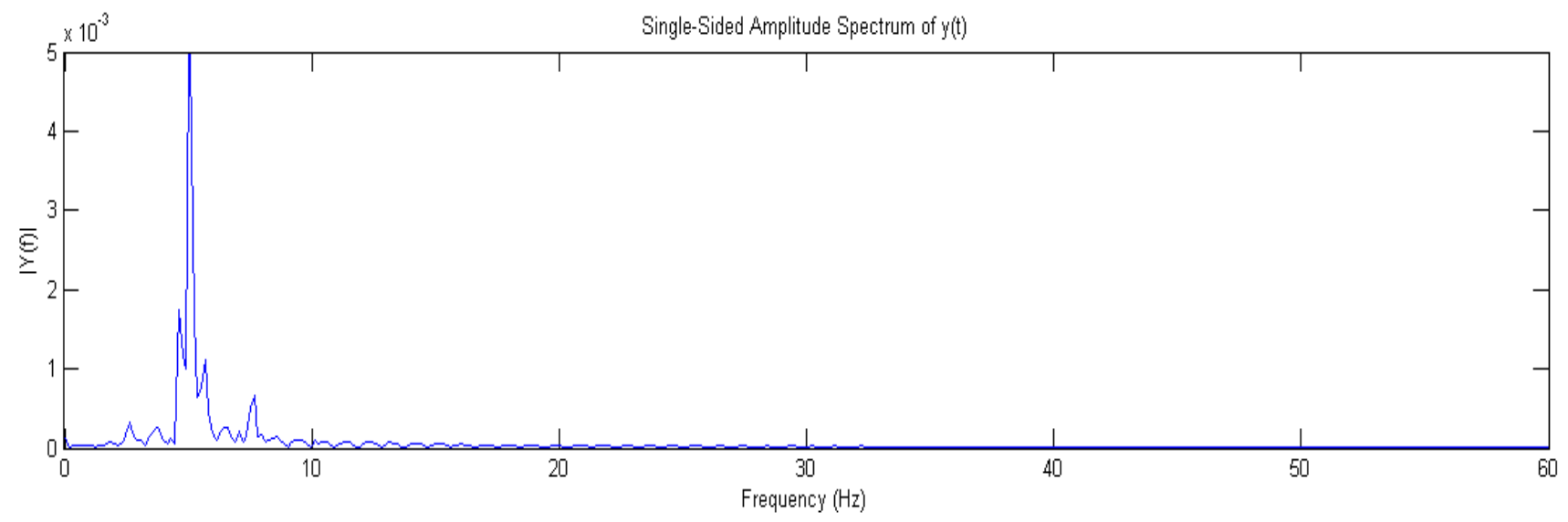

Figure 9. Mass Density of Two Blades Increased to $2000 \mathrm{~kg} / \mathrm{m}$ and $300 \mathrm{~kg} / \mathrm{m}$.

\subsection{Aerodynamic Imbalance Fault Simulations}

\subsubsection{Aerodynamic Asymmetry when Blades are at $0^{\circ}, 11.5^{\circ}$ and $11.5^{\circ}$}

In this case, three blades of turbine are made to work at different pitch angles i.e. blade $01=0^{\circ}$ blade 02 and blade $03=11.5^{\circ}$. Figure 10 depicts the effect of asymmetry in pitch angles via excitations are found at $1 \mathrm{P}$ frequency. 


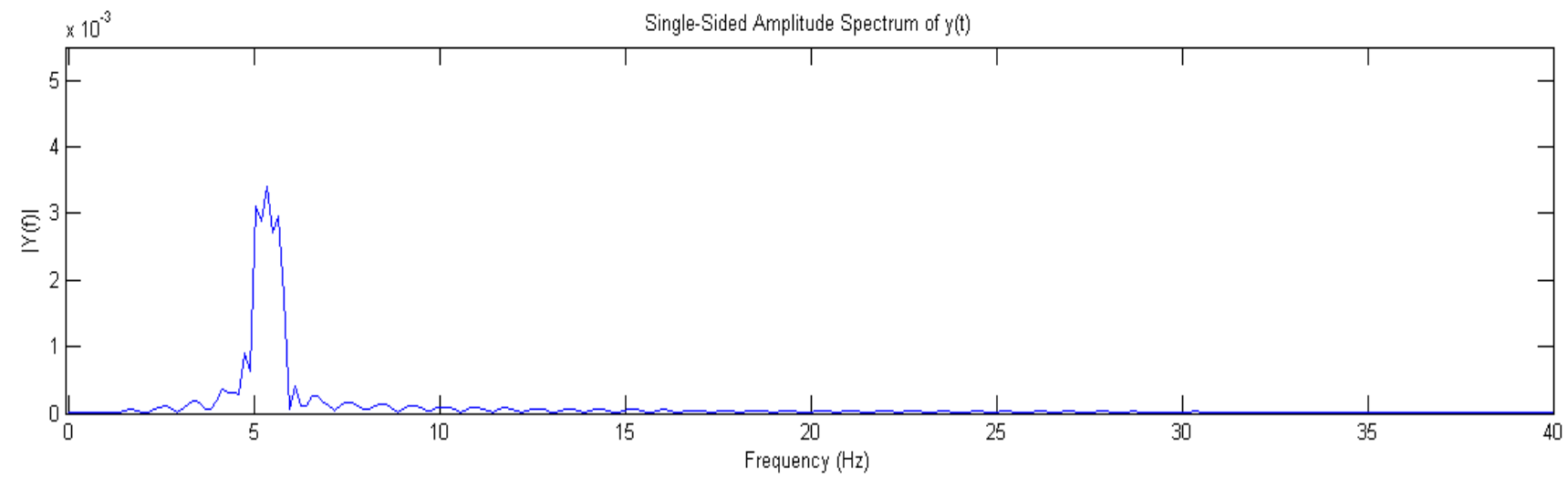

Figure 10. Aerodynamic Asymmetry when Blades are at $0^{\circ}, 11.5^{\circ}$ and $11.5^{\circ}$.

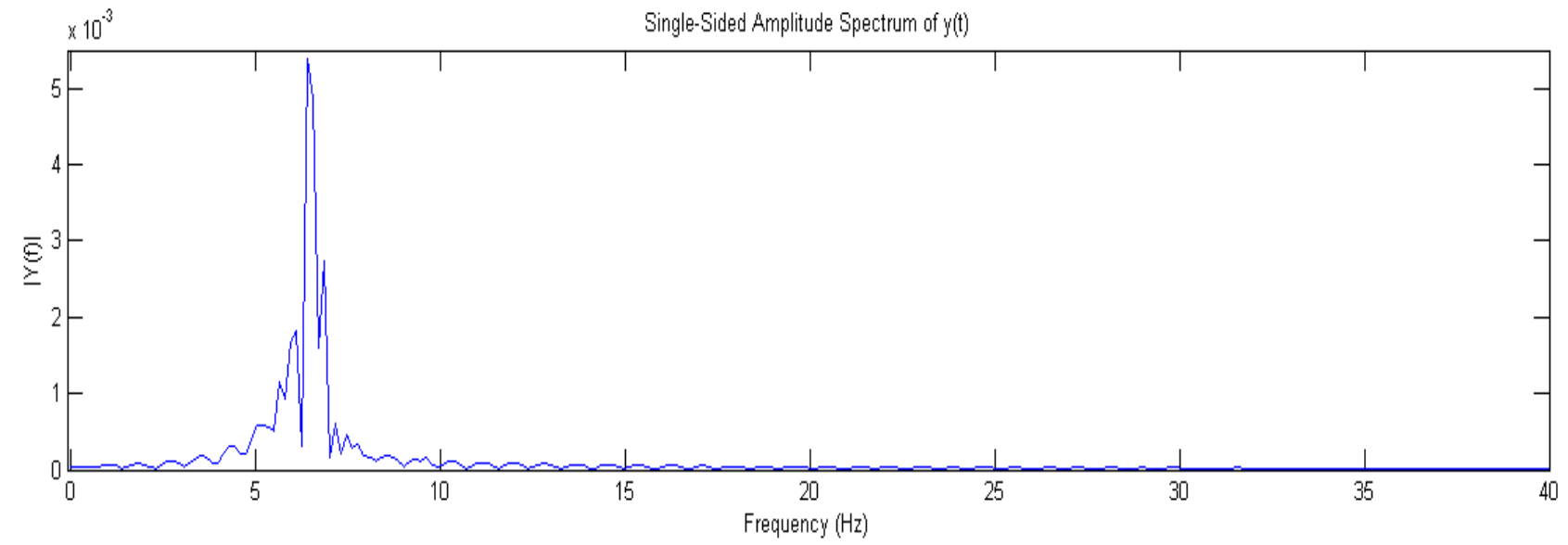

Figure 11. Aerodynamic asymmetry when blades are at $0^{\circ}, 0^{\circ}$ and $11.5^{\circ}$.

\subsubsection{Aerodynamic Asymmetry when Blades are at $0^{\circ}, 0^{\circ}$ and $11.5^{\circ}$}

In this case, two blades blade 01 and blade 02 are allowed to produce maximum torque i.e. at 0.0 degrees while pitch angle of blade 03 is set as 11.5 degrees. The effect of this configuration of blade pitch angles is shown in figure 11 .

\subsubsection{Aerodynamic Asymmetry when Blades are at $0^{\circ}, 0^{\circ}$ and $-7.5^{\circ}$}

In worst case scenario one of the blades has gone through complete pitch failure. Figure 12 shows the analysis of current signal when a blade is working in negative pitch angle. 


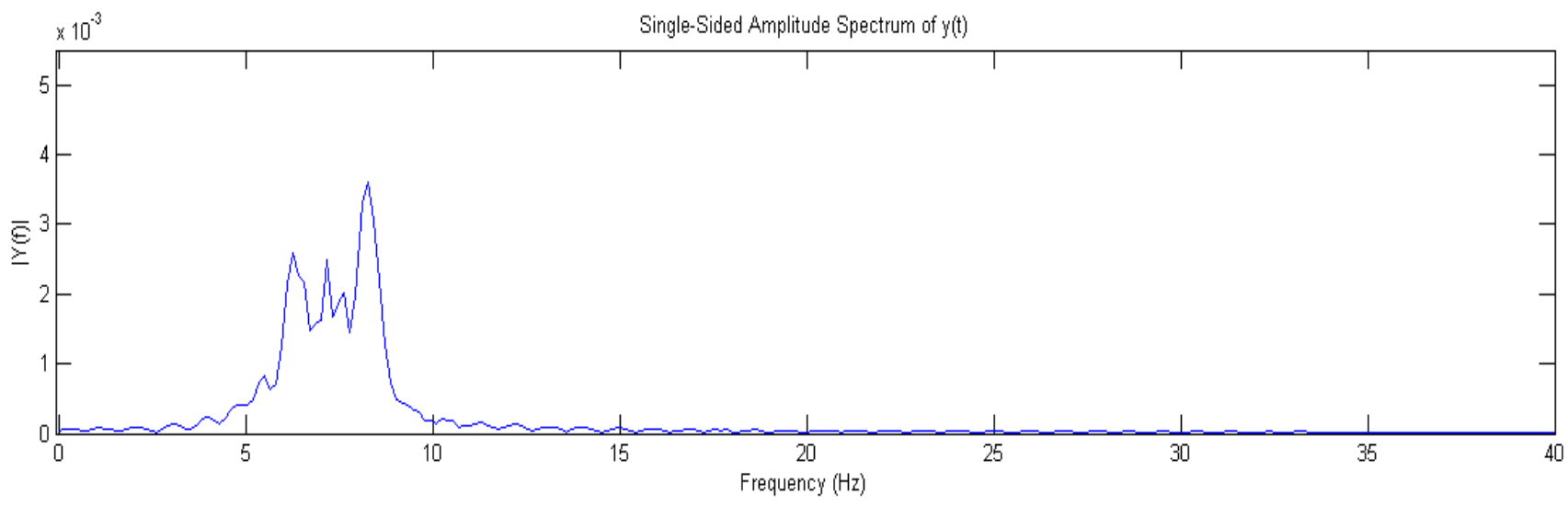

Figure 12. Aerodynamic Asymmetry when Blades are at $0^{\circ}, 0^{\circ}$ and $-7.5^{\circ}$.

\section{Conclusion}

This paper presents non-intrusive method of imbalance faults detection in horizontal axis wind turbines. It has been found that any vibrations appearing in mechanical system of turbine are evident from analysis of torque at main shaft. As main shaft of turbine is connected to that of electrical generator, consequently similar behavior is expected from generator's power signal. Basically the simulations have two major parts; one is to introduction of imbalance faults, which are mechanical in nature, in system and second is to analyze electrical system for specific signatures that represent imbalance fault in whole wind turbine system. A highly advanced software FAST (Fatigue, Aerodynamics, Structure and Turbulence) version 7.0 from National Renewable Energy Laboratory (NREL), a laboratory in U.S. Department of Energy is used to introduce blade and pitch imbalance faults in mechanical system of turbine. The data from this mechanical system is then fed into permanent magnet synchronous machine in Simulink. Simulations show that excitations in generators current signal appear at $1 \mathrm{P}$ frequency when wind turbine is subjected to any of imbalance faults. For sake of verification, multiple scenarios are tested like vary- ing mass of blades and varying pitch of blades at different scales. Each time, disturbances at $1 \mathrm{P}$ frequency are found. In this paper simple FFT analysis is adopted but various other analysis techniques can also be tested suitable for various operating/weather conditions of wind turbine.

\section{References}

1. Warne D F and Calnan P G. Generation of electricity from the wind. The Proceedings of the Institution of Electrical Engineers by IET. 1977 November; 124 (11): 963-85.

2. Whitby M. V164-8.0 MW breaks world record for wind energy production. MHI Vestas Offshore Wind official press release in month of October, 2014.

3. Gong X and Qiao W. Simulation investigation of wind turbine imbalance faults. International Conference on Power System Technology (POWERCON); October; 2010.

4. Jiang D, Huang Q, and Hong L. Theoretical and experimental study on wind wheel unbalance for a wind turbine. In Proc. World Non-Grid-Connected Wind Power and Energy Conference. 24-26, 2009 Sept.

5. Gong X and Qiao W. Imbalance fault detection of directdrive wind turbines using Generator current signals. IEEE Transactions on Energy Conversion. 2012 March; 27 (2): $468-76$. 
6. Jeffries W Q, Chambers J A, Infield D G. Experience with bi-coherence of electrical power for condition monitoring of wind turbine blades. IEEE Proceedings: Vision, Image Signal Process. 1998 June; 145 (3): 141-48.

7. Fadaeinedjad R, Moschopoulos G, Moallem M. The impact of tower shadow, yaw error, and wind shears on power quality in a wind diesel system. IEEE Trans. Energy Convers. 2009 March; 24 (1): 102-11.

8. Guo P and Infield D. Wind turbine tower vibration modeling and monitoring by the Nonlinear State Estimation Technique (NSET). Energies. 2012; 5: 5279-93.
9. Burton T, Sharpe D, Jenkins N, and Bossanyi E. Wind energy hand-book. In: Design loads for horizontal-axis wind turbines, Wiley Publ: New York; 2001.

10. Ramlau R and Niebsch J. Imbalance estimation without test masses for wind turbines. Journal of Solar Energy Engineering. 2009 Jan; 131 (1): 1-7.

11. Gardels D J, Qiao W, Gong X. Simulation studies on imbalance faults of wind turbines. Proc. IEEE Power Energy Soc. 2010 July; General Meeting: 1-5. 